\title{
Glycoconjugates of Polyhedral Boron Clusters
}

\author{
Dedicated to Professor Russell Grimes on the occasion of his $80^{\text {th }}$ birthday
}

\author{
Rashmirekha Satapathy ${ }^{* 1}$, Barada P. Dash ${ }^{* 2}$ Chandra Sekhara Mahanta ${ }^{1}$, Biswa Ranjan \\ Swain, ${ }^{1,2}$ Bibhuti Bhusan Jena ${ }^{1}$, \& Narayan S. Hosmane ${ }^{3}$ \\ ${ }^{1}$ Department of Chemistry, Ravenshaw University, Cuttack, Odisha, 753003, India \\ ${ }^{2}$ Department of Chemistry \& Centre for Nano Science and Nano Technology, Institute of \\ Technical Education and Research, Siksha 'O' Anusandhan University, Khandagiri \\ Square, Bhubaneswar, Odisha, 751 030, India \\ ${ }^{3}$ Department of Chemistry \& Biochemistry, Northern Illinois University, DeKalb, USA \\ *Author for correspondence:
}

Email: $\quad$ rashmi.satapathy@gmail.com $\quad$ (RS), $\quad$ barada.dash@gmail.com; baradadash@ soauniversity.ac.in (BD)

Keywords: Boron clusters, Carbohydrate, Carbohydrate mimetics, Cancer therapy, Glycoconjugates, Medicinal chemistry

\begin{abstract}
The potential medicinal applications of boron-based compounds have been well established. Among the medicinal applications of boron, its use for the treatment of cancer via boron neutron capture therapy (BNCT) is the most promising. Although a variety of approaches have been evaluated for adequate boron delivery to the cancer tissues for successful cancer therapy, this review focuses on the synthesis of carbohydrate-based boron delivery platforms. Recent advances in the synthesis and utilization of glycoconjugates for boron delivery has been reported.
\end{abstract}




\section{Contents}

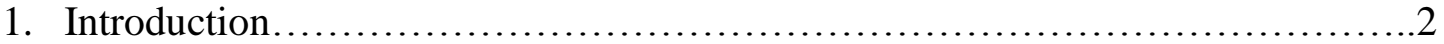

2. Glycoconjugates of carboranes........................................... 4

3. Glycoconjugates of carboranes for radiopharmaceutical applications.............16

4. Glycoconjugates of dodecaborate ion .................................. 19

5. Conjugates of carboranes with carbohydrate mimetics....................... 21

6. Conclusions ........................................................... 4 Acknowledgements References

\section{Introduction}

Glycochemicals have attracted significant interest for development of therapeutic agents and vaccines because of the functional and structural diversity of carbohydrates. Glycoconjugates and oligosaccharides have significant role in several biological processes such as cell growth, viral and bacterial infection, cell-cell communication and intercellular recognition processes [1,2]. Glycoconjugates have been used as targeted drug delivery systems in immunoactivation, enzyme replacement, antiviral, gene and cancer therapies. Such glycotargeting of drugs relies on the presence of carbohydratespecific receptor proteins on the cell surface and over expression of lectins on tumor tissues [3-5]. Thus glycoconjugates of polyhedral boron clusters have been synthesized for tumor targeted delivery of boron for successful treatment of cancer via boron neutron capture therapy (BNCT) [6].

The medicinal chemistry of boron drugs for cancer treatment relies on the boron neutron capture reaction that involves a ${ }^{10} \mathrm{~B}$ atom capturing a thermal neutron giving an excited ${ }^{11} \mathrm{~B}$. The excited ${ }^{11} \mathrm{~B}$ undergoes a rapid fission reaction producing high energy ${ }^{4} \mathrm{He}^{2+}(\alpha-$ particle) and ${ }^{7} \mathrm{Li}^{3+}$ ions that kills the cancer cells [7]. The therapeutic dose of ${ }^{10} \mathrm{~B}$ required to kill a cancer cell is $\sim 10^{9}$ atoms per cell or about $30 \mu \mathrm{g} / \mathrm{gram}$ of tumor. Therefore, an 
important requirement for an effective BNCT depends on selectively directing the requisite concentrations of ${ }^{10} \mathrm{~B}$ to the cancerous tissues and sparing the surrounding healthy tissues. The high linear energy transfer of the emitted $\alpha$-particle and the recoil lithium particle in biological tissues is $\sim 4-9 \mu \mathrm{m}$ which is approximately the diameter of a cell. Therefore, these high energy particles dissipate their kinetic energy before traveling one cell diameter so that the destructive effect is highly localized only to the boronloaded tissue [8]. Although BNCT has been primarily used for the treatment of fatal malignant brain cancers such as glioblastoma multiforme [9], ${ }^{5}$ it is now being extended to the treatment of other types of cancers such as melanoma [10], ${ }^{6}$ and head and neck cancer [11]. Based on the same principle treatment of rheumatoid arthritis ${ }^{8}$ could be possible via boron neutron capture synovectomy (BNCS) [12].

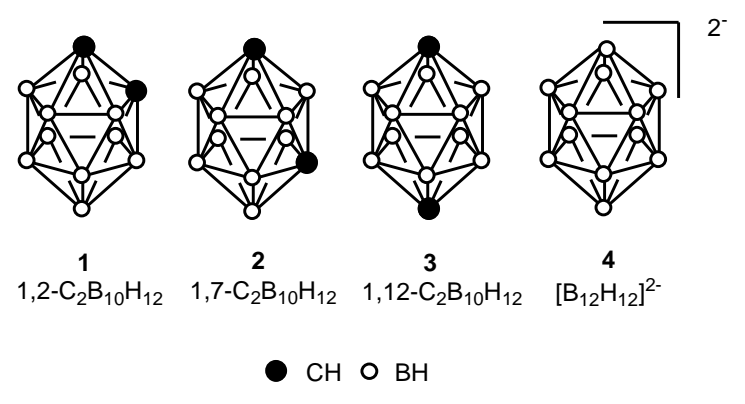

Figure 1. Icosahedral boron compounds

In recent years, the applications of polyhedral boron compounds specifically icosahedral boron clusters [13] (Figure 1) in medicinal chemistry receives increasing attention. Other than BNCT for cancer therapy, these compounds have been used as stable hydrophobic pharmacophores, retinoid receptor ligands, steroid analogs, human blood platelet function inhibitors and HIV protease inhibitors [7-12]. All four clusters shown in Figure 1 possess high chemical and biological stability, rigid geometry and low toxicity. The presence of 10-12 boron atoms in these compounds would make the task of achieving necessary 
therapeutic concentration of boron atoms in the tumor tissues easier. Dicarba-closododecacarboranes $\left(\mathrm{C}_{2} \mathrm{~B}_{10} \mathrm{H}_{12}\right)$ (1-3) are characterized by an exceptional hydrophobic character whereas, closo-dodecaborate $\mathbf{4}$ possesses ionic and hydrophilic characteristics. However, the functionalization of hydrophobic ortho, meta and para carboranes (1-3) are much easier than the hydrophilic dodecaborate ion which prevents its wider application in synthetic and medicinal chemistry [14]. Polyhedral boron compounds have been conjugated with several tumor targeting moieties such as nucleic acid precursors, amino acids, peptides, lipids, carbohydrates, nanoparticles, lipoproteins, liposomes, porphyrins, DNA binders, polyamines, antigen binders, amines, hydantoins and barbiturates etc. for targeted boron delivery to tumor tissues [15]. There are a number of reviews available on the synthesis of conjugates of carboranes as boron delivery platforms and their various medicinal applications $[7,8,14,15]$. In addition to their medicinal applications, carboranes have also been utilized in various other applications such as in organometallic chemistry, catalysis and materials science those are described elsewhere [16]. In this paper, we have only reviewed recent advances in the synthesis and medical applications of glycoconjugates of polyhedral boron compounds.

\section{Glycoconjugates of carboranes}

Glycoconjugates of carboranes were first synthesized a couple of decades ago by Hawthorne's group. It was initially thought that the hydrophilic characteristics of carbohydrates could compensate the hydrophobicity of carboranes [17]. Typically two general synthetic approaches are followed for synthesis of C-substituted $o$-carboranes. One is the reaction of substituted alkynes with decaborane $\mathrm{B}_{10} \mathrm{H}_{14}$ under appropriate conditions and the other is the reaction of lithiated $o$-carborane with an electrophilic 
moiety [15]. The first approach was followed for the synthesis of the reported compound 3'-O-(o-carboran-1-ylmethyl)-D-glucose (5). It was obtained as an anomeric mixture and water-insoluble. It has been reported that a minimum of eight hydroxyl groups per carborane cage is required to impart water solubility. Compound $\mathbf{5}$ contains only five hydroxyl groups, three less than the required number to make it water soluble [15b]. However, it showed remarkable biological properties. The cellular uptake studies of $\mathbf{5}$ was carried out using rat glioma cells F98 and compared with clinically used BNCT drug sodium mercaptoundecahydro-closo- dodecaborate (BSH) 6 (Figure 2). One example of higher cellular uptake of carbohydrate based boron delivery platform is in the case of compound 13 (Scheme 1). Cellular boron uptake up to $65 \mu \mathrm{g} / \mathrm{gram}$ cells was achieved by using compound $\mathbf{1 3}$ whereas only $2 \mu \mathrm{g} / \mathrm{gram}$ cells boron uptake was observed for BSH (Figure 2) [18]. The higher cellular uptake via the glycosylated carborane derivatives made such compounds promising candidates for tumor targeted boron delivery and thus synthesis and biological evaluation of several such derivatives followed.

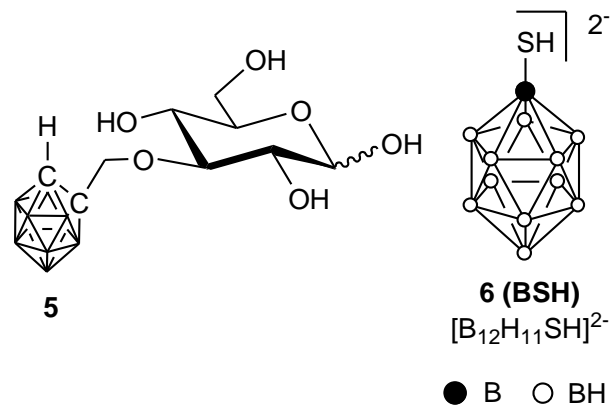

Figure 2. Carboranyl derivative of D-glucose $\mathbf{5}$ and clinically used BNCT drug sodium mercaptoundecahydro-closo- dodecaborate (BSH) 6.

The synthesis of water-soluble glycoconjugates of carboranes for targeted boron delivery to tumor tissues was reported by Tietze and Bothe [19]. They synthesized glycoconjugates of $O$-carborane with both monosaccharides (glucose and mannose) and 
disaccharides (lactose and maltose). These conjugates were synthesized from their respective trichloroimidates. The reaction of glucose trichloroimidate (7) with either 3butyn-1-ol or 5-hexyn-1-ol in the presence of $\mathrm{BF}_{3} \cdot \mathrm{Et}_{2} \mathrm{O}$ afforded butyl $\beta$-glucoside (8a) and hexynyl $\beta$-glucoside (8b) respectively. $O$-carborane moieties were then appended to the alkynyl glucosides via reaction with decaborane in acetonitrile under reflux condition (Scheme 1). The deprotection of the peracetylated glucosides 9a and 9b with sodium methoxide/ methanol resulted in the desired carboranyl glucosides 10a and $\mathbf{1 0 b}$. Carboranyl mannoside (11), carboranyl lactoside (12) and carboranyl maltoside (13) were synthesized following similar synthetic procedures. Carboranyl monosaccharides $\mathbf{1 0}$ and 11 were not sufficiently water-soluble as compared to the disaccharides $\mathbf{1 2}$ and $\mathbf{1 3 .}$
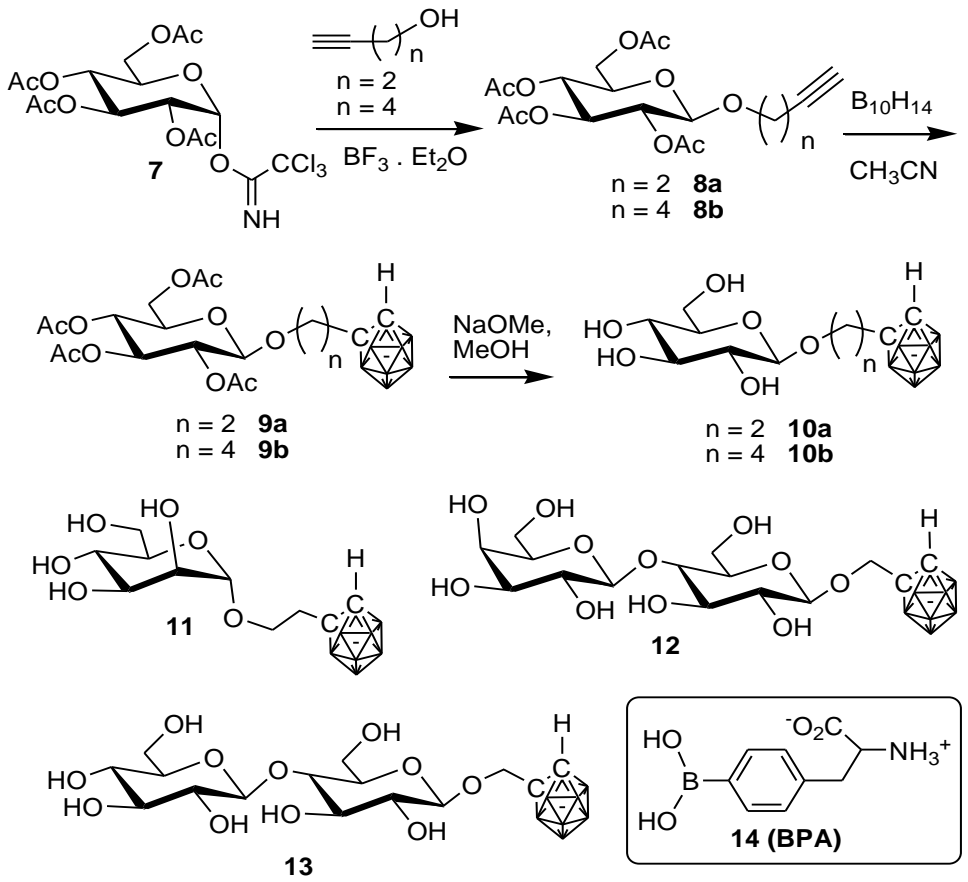

\section{Scheme 1. $O$-carboranyl glycosides of glucose, mannose, maltose and lactose and clinically used BNCT drug 4-boronophenylalanine (BPA) 14.}

The toxicity evaluation of water-soluble compounds 12 and $\mathbf{1 3}$ were carried out using human bronchial carcinoma cell line A549 and found that they showed no toxicity up to 
$0.40 \mathrm{mM}$ concentration. The boron uptakes of carboranyl monosaccharide 10a, and carboranyl disaccharide $\mathbf{1 2}$ and $\mathbf{1 3}$ were evaluated using B16 melanoma cells and the results were compared with clinically used boron drug 14 (BPA). Carboranyl maltoside 13 exhibited highest uptake among the carboranyl glycosides 10a, 12 and $\mathbf{1 3}$ used for the study. For compound $\mathbf{1 3}$ boron accumulation at $3 \mathrm{~h}$ after administration was $6.1 \mathrm{ppm}$ and it was increased up to $20.0 \mathrm{ppm}$ after $24 \mathrm{~h}$. In the case of lactoside 12, the boron concentration was $11.7 \mathrm{ppm}$ at $3 \mathrm{~h}$ and reached $13.2 \mathrm{ppm}$ at $12 \mathrm{~h}$ and remained almost constant until $24 \mathrm{~h}$. Whereas for carboranyl monosaccharide 10a the boron accumulation the cells reached the maximum value $11.2 \mathrm{ppm}$ at $3 \mathrm{~h}$ and then gradually decreased. These values were significantly higher than that observed for BPA 14 which was only 3.1 ppm after 24 hours. The in vitro survival of C6 glioma cells after thermal neutron irradiation indicated that maltoside $\mathbf{1 3}$ to be more effective than ${ }^{10} \mathrm{~B}$ enriched BSH [20].
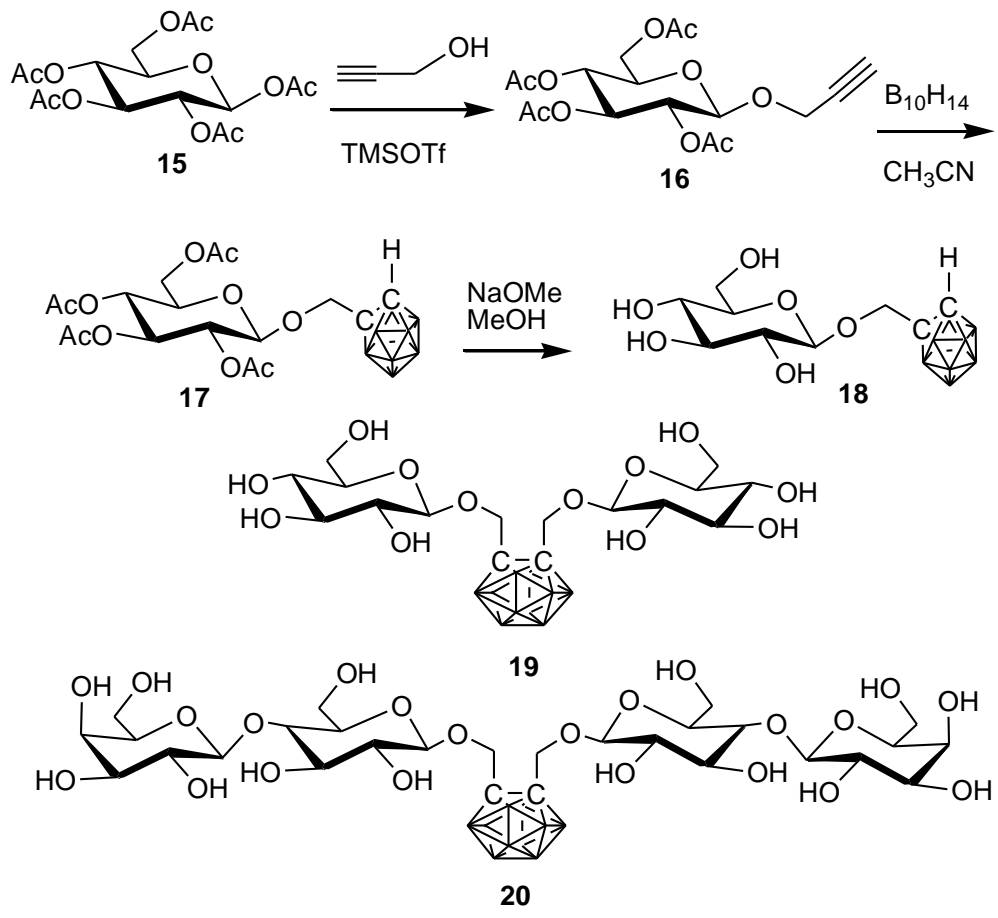

Scheme 2. $O$-carboranyl glycosides from peracetylated glucose and lactose derivatives 

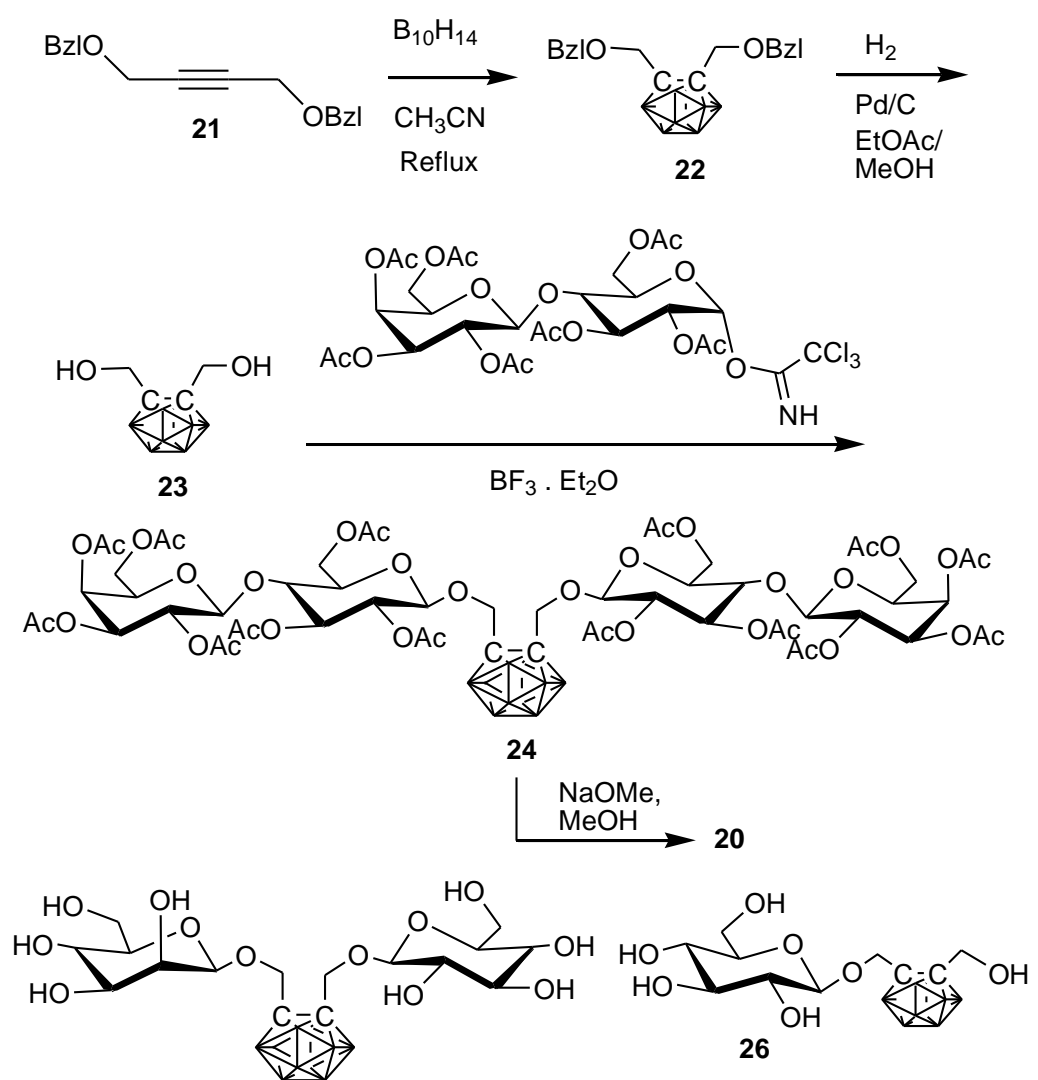

25

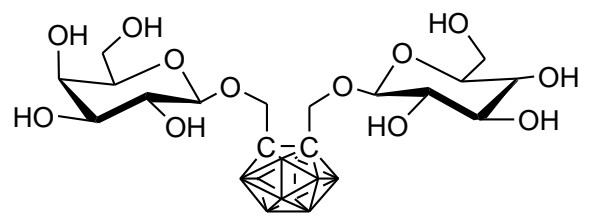

27

Scheme 3. Symmetrical and unsymmetrical $o$-carboranyl bisglycosides containing lactose, glucose, mannose and galactose

Compound $\mathbf{1 7}$ which is similar to 9a was synthesized via trimethyl silyl triflate glycosidation of pentaacetyl-D-glucose $\mathbf{1 5}$ with 2-propyn-1-ol. The alkenyl derivative $\mathbf{1 6}$ obtained during the reaction was further treated with decaborane and deprotected with sodium methoxide/methanol solution to produce the desired carboranyl glycoside $\mathbf{1 8}$. Compound 12 containing a lactose moiety appended to the o-carborane cluster was also synthesized via similar method. In addition, to improve the water solubility 2-butyn-1,4- 
diol was used as the precursor for the synthesis of compounds $\mathbf{1 9}$ and $\mathbf{2 0}$ containing two hydrophilic glucose and lactose moieties surrounding the hydrophobic o-carborane cluster (Scheme 2). However, the overall yields of compounds $\mathbf{1 9}$ and 20 prepared via this method appear to be low [21].

$O$-carboranyl bisglycosides containing either lactose or glucose moieties or mixed bisglycosides on both sides of the lipophilic $o$-carborane have been synthesized in an efficient manner and their biodistribution studies have been carried out [22]. As shown in Scheme 1, lactose trichloroacetimidate and glucose trichloroacetimidate have also been used in this case for the synthesis of glycosylated $o$-carborane derivatives. Benzylated butynyl diol 21 was refluxed with decaborane $\left(\mathrm{B}_{10} \mathrm{H}_{12}\right)$ in acetonitrile to produce the carboranyl diol 22. Hydrogenolysis with $\mathrm{Pd} / \mathrm{C}$ led to the diol $\mathbf{2 3}$ in good yield. Stereoselective reaction of $\mathbf{2 3}$ with lactose trichloroacetimidate in the presence of $\mathrm{BF}_{3} . \mathrm{Et}_{2} \mathrm{O}$ resulted in the formation of $\mathbf{2 4}$ in much better 68\% yield. Solvolysis of $\mathbf{2 4}$ using sodium methoxide/methanol solution produced the desired carboranyl bislactoside $\mathbf{2 0}$ in moderate $46 \%$ overall yield (Scheme 3). Following similar procedure several glycosylated $o$-carborane derivatives such as carboranyl bisglucoside 19 (Scheme 2), mixed bisglycoside 25 containing both glucose and mannose moieties, carboranyl alcohol 26 containing glucose moiety and mixed bisglycoside 27 containing glucose and galactose moieties were synthesized in good yields (Scheme 3). The biodistribution and in vitro thermal neutron irradiation of $\mathbf{2 5 ,} \mathbf{2 7}$ and $\mathbf{1 3}$ have been carried out using B16 melanoma and C6 glioma cells and the results have been compared with BSH and BPA. Bisglycosides 25 and $\mathbf{2 7}$ showed no cytotoxicity up to $0.50 \mathrm{mM}$ concentration. The B16 melanoma cells were incubated with a medium containing glycosides 25,27 and 13 at 
10.8 and 54 ppm boron concentrations. The mixed glycosides $\mathbf{2 5}$ and $\mathbf{2 7}$ showed very low boron uptake $(<1 \mathrm{ppm})$ even after 24 hours of incubation whereas maltoside $\mathbf{1 3}$ showed boron uptake of $20 \mathrm{ppm}$. In comparison BPA showed only $3.1 \mathrm{ppm}$ boron uptake. Similar results were obtained for C6 glioma cells and of boron uptake for mixed glycosides $\mathbf{2 5}$ and 27 were found to be negligible. However, maltoside $\mathbf{1 3}$ showed the highest uptake up to $48 \mathrm{ppm}$. The low uptake observed for mixed glycosides $\mathbf{2 5}$ and $\mathbf{2 7}$ has been attributed to the enzymatic cleavage of $O$-glycosylated carboranes by glycohydrolases [22].
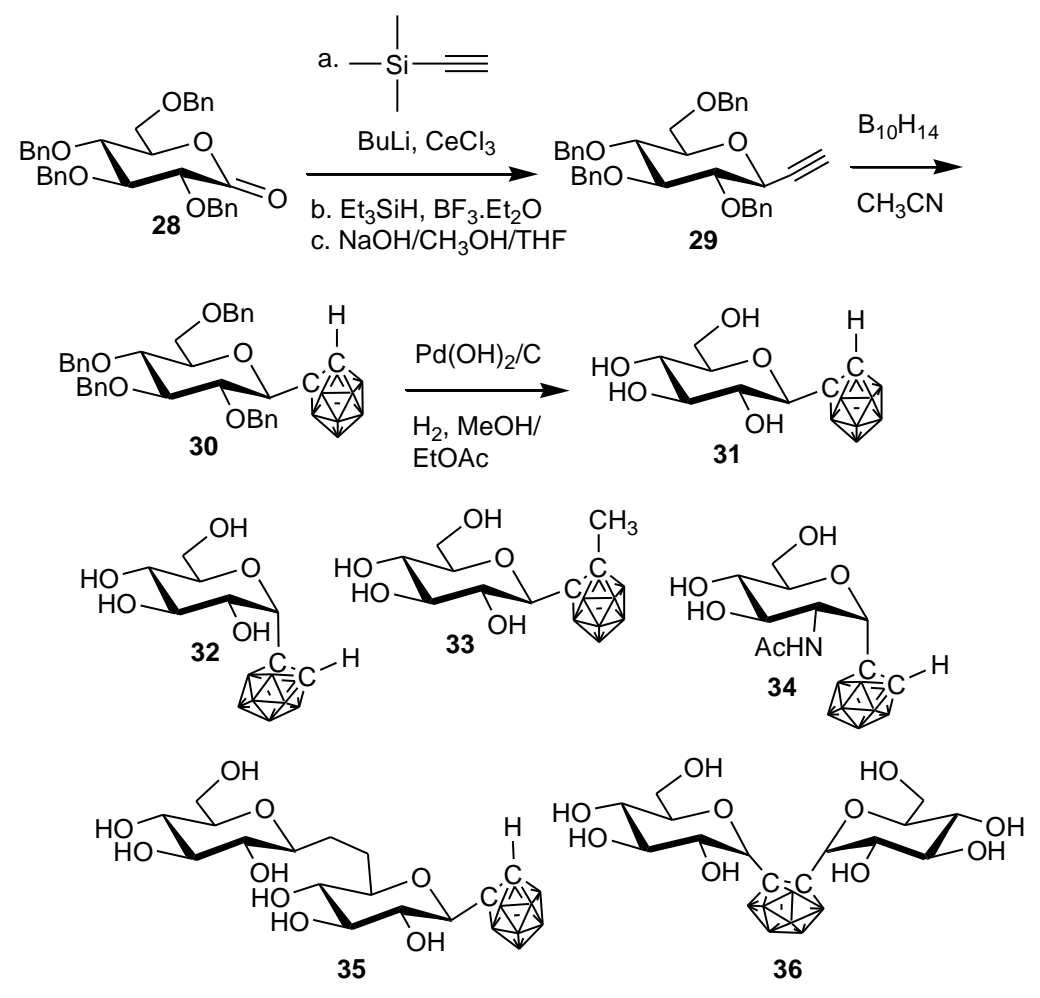

Scheme 4. Synthesis of carboranyl $C$-glycosides and bisglycosides

To overcome the disadvantage of $O$-glycosylated carboranes, $C$-glycosylated carboranes have been synthesized. The earlier reported $C$-glycosylated carborane compound $\mathbf{5}$ (Figure 2) was obtained as an anomeric mixture and showed much improved cellular uptake than BSH [18]. Tietze et al have reported the stereoselective synthesis of $C$ glycosylated carborane derivatives starting from perbenzylated gluconolactones. The 
reaction sequence followed addition of cerium TMS-acetylide, deoxygenation with trtethyl silane/boron trifluoride etherate, cleavage of the TMS group and finally treatment of the resulting alkyne with decaborane in acetonitrile (Scheme 4). The cytotoxicities of carboranyl C-glycosides 31-35 were determined using MTT test using four different cell lines such as human bronchial carcinoma A549, murine melanoma B-16, human pancreas carcinoma PancTu1 and human colon rectal adeno carcinoma cells LoVo. The cytotoxicities have been reported as $\mathrm{ED}_{50}$ (drug concentration required for $50 \%$ effect on target cells) and the highest cytotoxicity ( $\mathrm{ED}_{50}$ between $\left.0.124-0.291 \mathrm{mM}\right)$ was observed for 33 whereas the lowest $\left(\mathrm{ED}_{50}>1.1 \mathrm{mM}\right)$ was observed for carboranyl $C$-gentiobiose $35[23]$.
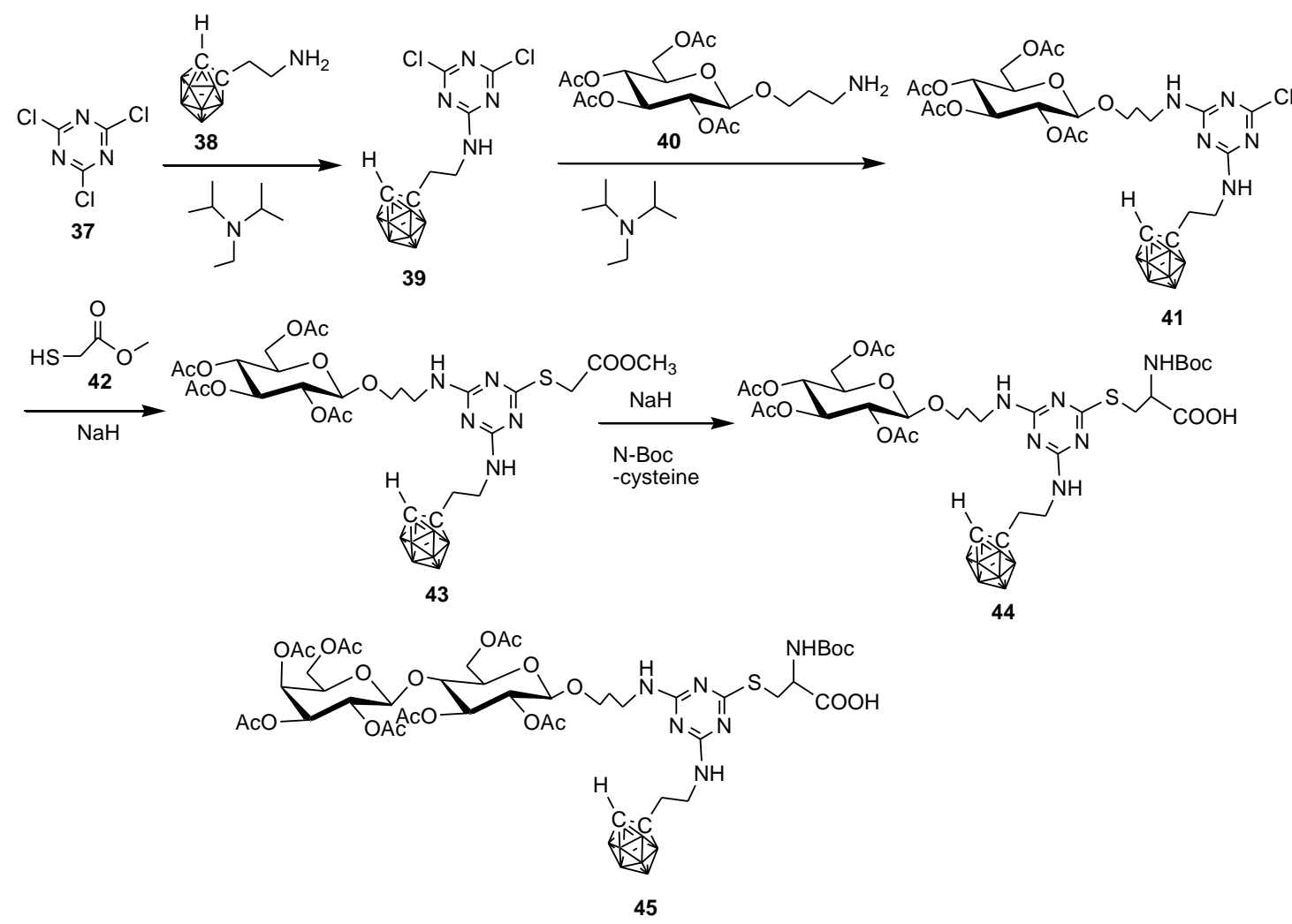

Scheme 5. Synthesis of carborane-sugar conjugates on a triazine scaffold

Combinatorial approach has been adopted to synthesize efficient BNCT agents starting from cyanuric chloride. In addition to $o$-carborane clusters, sugar and amino acid 
moieties have been appended to cyanuric chloride scaffold. In general, sugars impart water-solubility and carboxylic acid part of the amino acid would make this molecule ready for conjugation with biopolymers. Cyanuric chloride was treated with 2-carboranyl amino ethane $\mathbf{3 8}$ and the amino glucose derivative $\mathbf{4 0}$ in the presence of Hunigs' base to produce disubstituted triazine $\mathbf{4 1}$ containing $o$-carborane and glucose moieties. Further treatment with methyl thioglycolate and $\mathrm{N}$-Boc-cysteine resulted in the desired trisubstituted compound $\mathbf{4 4}$ containing a carboxylic acid moiety. Similar procedure was followed to synthesize 45 containing a lactose moiety (Scheme 5) [24].
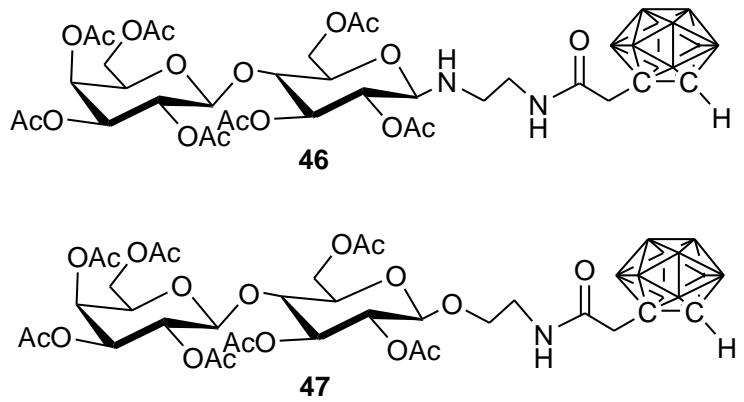

Figure 3. $O$-Carborane-lactose conjugates with $N$-glycosidic and $O$-glycosidic linkages $O$-Carborane-lactose conjugates via $\mathrm{N}$-glycosidic and $O$-glycosidic linkage were synthesized starting from carboranyl acetic acid. The $N$-glycosidic conjugate 46 was found to be more stable against hydrolytic deboronation (closo to nido transformation of the $o$-carborane cage) under neutral conditions than the conjugate 47 formed with $O$ glycosidic linkage (Figure 3). Therefore, the hydrolytic stability of carboranecarbohydrate conjugates in neutral aqueous solutions depends on the chemical nature of the spacer that links the carbohydrate moiety with the boron cage. This phenomena has been attributed to the formation of more strongly bound supramolecular aggregates in case of $o$-carborane-lactose conjugates formed via $\mathrm{N}$-glycosidic linkage that makes boron cages less accessible to nucleophilic attack by solvent molecules [25]. 
The condensation reaction of nitro acetylanthranilic acid $\mathbf{4 8}$ with aminophenylcarborane 49 gave 50 which upon reduction with $\mathrm{Na}_{2} \mathrm{~S}$ led to the corresponding amino derivative 51. Reaction of compound $\mathbf{5 1}$ with D-glucose or D-ribose in methanol in the presence of a catalytic amount of acetic acid afforded boronated $N$-glycosylaminoquinazolines $\mathbf{5 2}$ and 53 respectively. Decapitation of $o$-carborane cage of compounds $\mathbf{5 2}$ and $\mathbf{5 3}$ yielded highly water-soluble nido carboranyl compounds 54 and 55 (Scheme 6). The in vitro toxicity test using B16 melanoma cells showed that the highly water soluble nidoundecaboranylquinazolines (54 and 55), were nontoxic at boron concentration up to 3000 $\mu \mathrm{g}$ boron $\mathrm{ml}^{-1}$, whereas, closo-carboranylquinazolines (52 and 53) have $\mathrm{LD}_{50}$ (Drug concentration required for $50 \%$ killing of target cells) $>200 \mu \mathrm{g}$ boron $\mathrm{ml}^{-1}$. Therefore these compounds may be considered as potential BNCT agents [26].

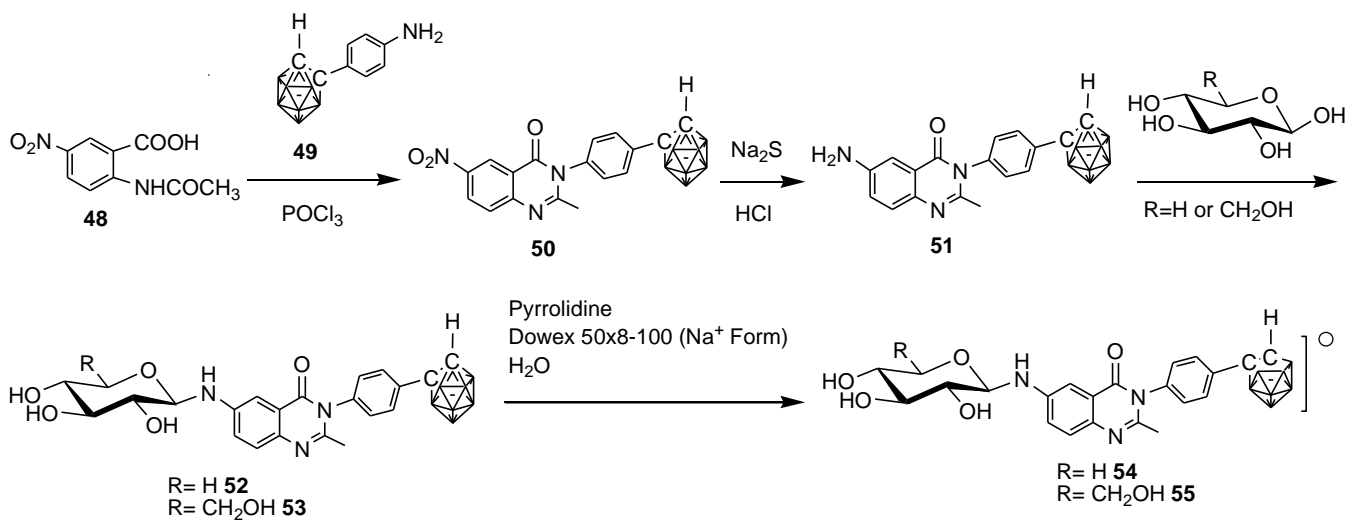

Scheme 6. Synthesis of $N$-glycosyl caboranylquinazolines

Galactosyl group typically binds to the surface of a tumor cells due to the overexpression of lactose-binding lectins on the surface of tumor cells. Incorporation of galactosyl moieties into BNCT agents could enhance their uptake into tumor tissues. Therefore, glycophosphonates derivatives of carboranes $\mathbf{5 6}$ and $\mathbf{5 7}$ containing galactose moieties and phosphonate groups have been synthesized by using phosphoramidite [27] method 
starting from meta- or para-carboranyl bis(phosphonite) and protected galactose in the presence of benzimidazolium triflate (BIT). After deprotection of the phosphonate, the isopropylidene groups of the galactose moieties were cleaved with trifluoroacetic acid/water (9:1) and subsequently converted into the desired disodium salts by ion exchange [28].
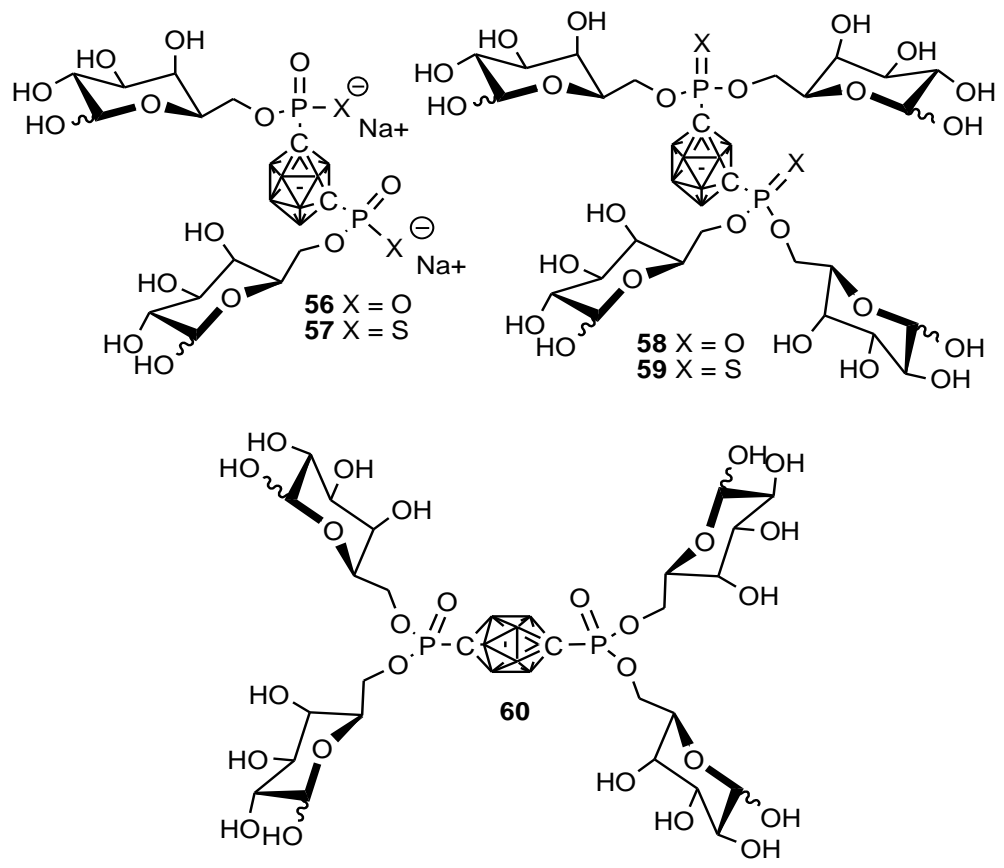

Figure 4. Water soluble bis(phosphonate), bis(phosphonothionate), and bis(glycophosphonate) of carborane

Tetra-D-galactosylated carboranediyl bis(phosphonates) containing four galactose moieties 58-60 (Figure 4) were also synthesized in a like manner. However, these were synthesized from a different starting material possessing four dimethylamido groups. The synthesis of bis-glycophosphonates and phosphonothioates of meta and para-carboranes was then extended to the bis(meta-carborane) to increase the boron content in such compounds (Figure 5). Employing similar methodology as reported in their previous work, compounds 61-62 containing two galactose moieties and compounds 63-64 
possessing four galactose moieties were synthesized [29]. The introduction of the biscarborane units in compounds 61-64 enhanced the hydrophobicity of these compounds and these were found to be less water-soluble than the carborane derivatives 56-60. Therefore, the cytotoxicities of 61-64 were higher than 56-60 [28, 29].
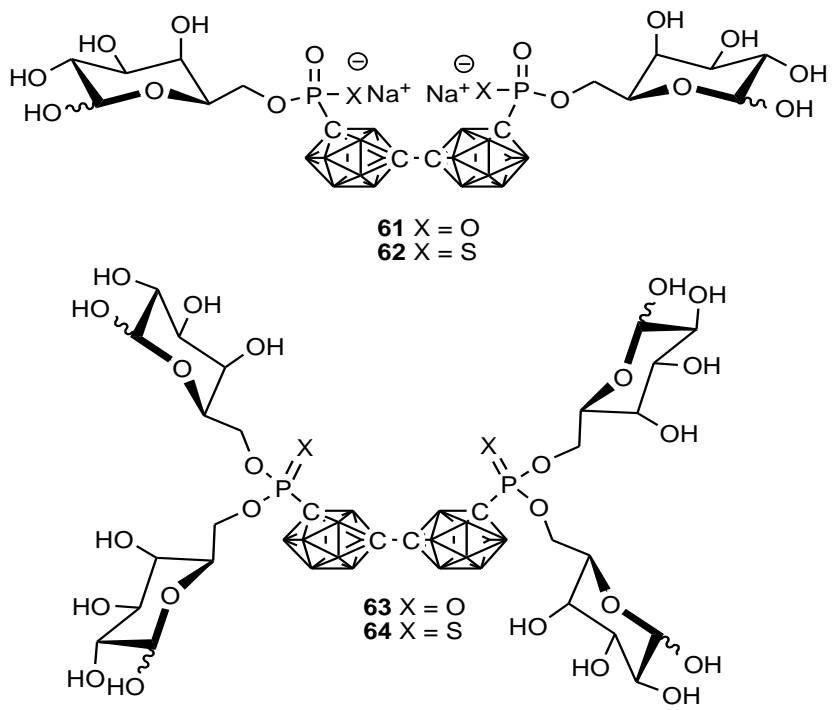

Figure 5. Bis-carborane-bridged bis-glycophosphonates and phosphonothioates

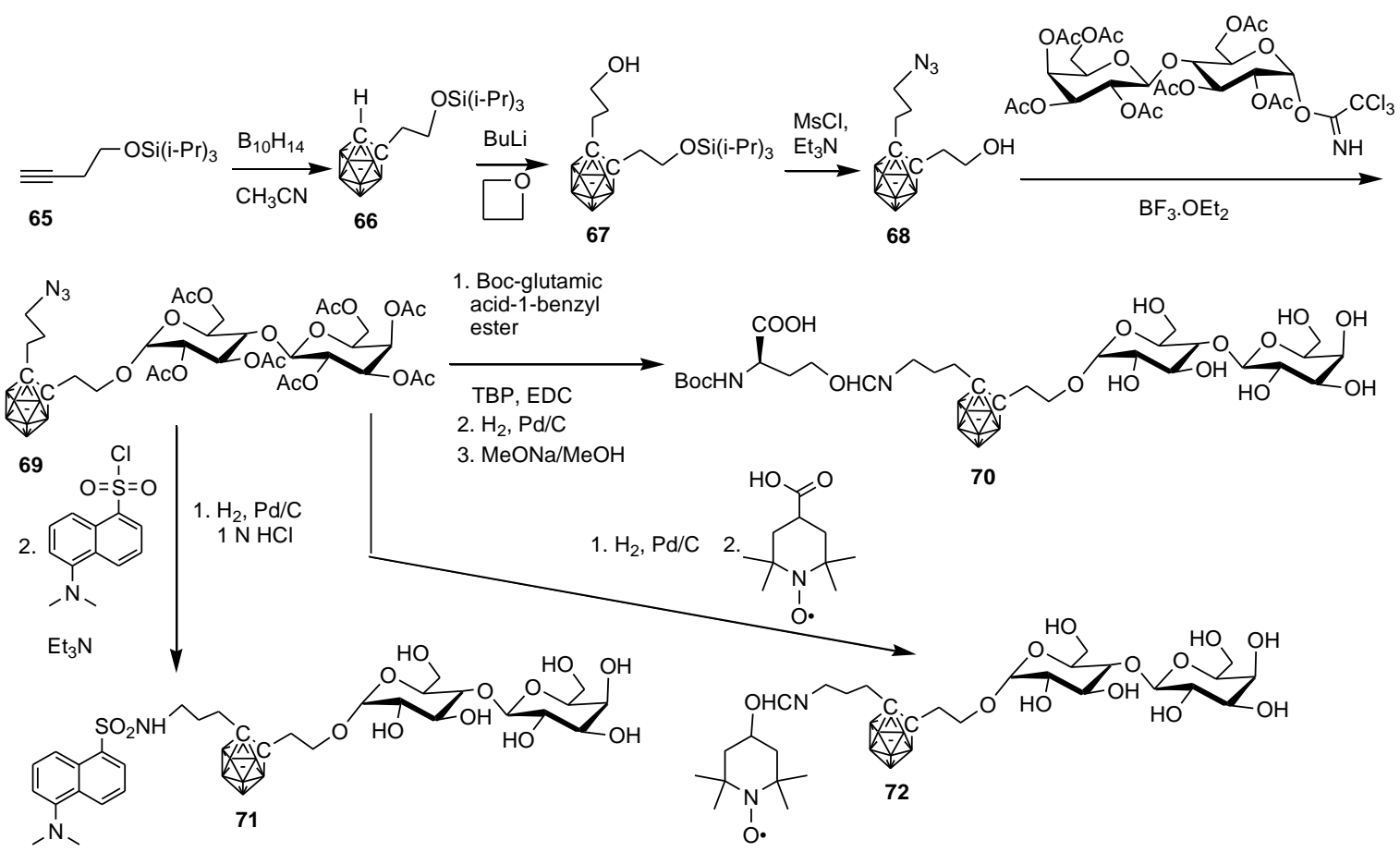

Scheme 7. Synthesis of complex glycosylated carboranes via azido derivative 
New galactosyl derivatives of $o$-carborane have also been recently synthesized starting from triisopropylsilyl ether of 3-butyn-1-ol 65. The carboranyl derivative $\mathbf{6 6}$ was prepared by refluxing 65 with decaborane in the presence of acetonitrile. Alkylation of $\mathbf{6 6}$ with oxetane gave monoprotected diol $\mathbf{6 7}$ in good yield which then transformed to the azido derivative 68 via mesylation and treatment with tetrabutylammonium azide. After deprotection of the silyl ether with TBAF buffered with acetic acid, compound $\mathbf{6 8}$ was glycosylated with peracetylated lactosyl trichloroacetimidate in the presence of $\mathrm{BF}_{3} \cdot \mathrm{Et}_{2} \mathrm{O}$ affording intermediate 69. Starting from 69, amino acid functionalized derivative 70, dansyl derivative $\mathbf{7 1}$ and nitroxide $\mathbf{7 2}$ were obtained following different synthetic procedures (Scheme 7) [30a]. The surface of tumor cells is typically characterized by an increased concentration of galectins, the proteins that bind $\beta$-galactose moieties. Thus, glycoconjugates of polyhedral boron compounds containing lactose or $\beta$-galactose moieties are considered as potential compounds for selective binding to tumor cells via carbohydrate-protein interactions. Therefore, a variety of glycoconjugates of $o$-carborane and dodecaborate ion containing $\beta$-lactosylamine or $\beta$-D-galactopyranosylamine derivatives with the terminal amino group spacer have been synthesized. It was observed that, glycoconjugates with an $O$-linked $\beta$-galactose as a fragment of lactosylamine bind to galectin much more efficiently than the corresponding glycoconjugates with $N$-linked $\beta$ galactose moiety. The glycoconjugates containing one $\beta$-lactosylamine moiety bind to galectin approximately two times less efficiently than glycoconjugates containing lactose moiety. However, introduction of the second and third $\beta$-lactosylamine moieties into the glycoconjugate increases the binding efficiency by a factor of five to seven due to the cluster effect [30b-d] 


\section{Glycoconjugates of carboranes for radiopharmaceutical applications}

Development of molecular radioimaging probes has been receiving increasing interest because of the high sensitivity offered by nuclear imaging methods. Thus imaging techniques such as single photon emission computed tomography (SPECT) and positron emission tomography (PET) that uses such probes can monitor disease development at their very early stages [31]. The two important components for the synthesis of targeted radiopharmaceutical are a vector for achieving high target-to-non-target ratio and a ligand for robust covalent linkage between the targeting moiety and the radionuclide. Since ${ }^{18} \mathrm{~F}$ labeled analogue of glucose ${ }^{18} \mathrm{~F}$-2-deoxy-2-fluoro-D-glucose $\left({ }^{18} \mathrm{FDG}\right)$ is used to detect sites of increased glucose metabolism and as a tracer for cancer imaging using positron emission tomography (PET), glucose moieties could act as vector for radiopharmaceuticals [32]. In addition, the deboronated ortho-carborane clusters could also be utilized as ligands to produce targeted radiopharmaceuticals. It can produce stable form of $\eta^{5}$-complexes with a variety of metals [33]. Therefore, carborane-carbohydrates conjugates have been used for radiopharmaceuticals applications.

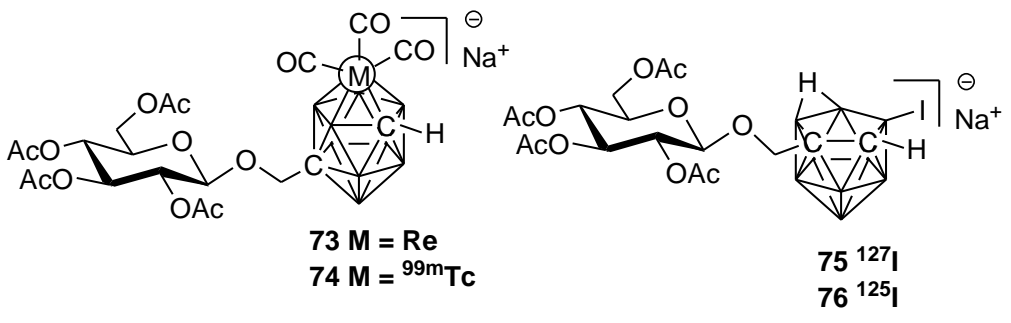

Figure 6. Glycosylated carboranes with radiolabelled Tc and I

Organometallic complexes of ${ }^{99 \mathrm{~m}} \mathrm{Tc}$ have been widely used in diagnostic medicine [34]. Since Re and Tc exists in the same group of the periodic table, a variety of Re and ${ }^{99} \mathrm{Tc}$ carborane complexes have been prepared using mild tetraethyl ammonium fluoride (TEAF) as the reagent instead of using strong bases like KF or $\mathrm{NaH}$ [35]. Examples of 
radiolabelled carboranyl sugar derivatives synthesized via deboronation of $\mathbf{1 8}$ (Scheme 2) have been shown in Figure 6 . Prior to radiolabelling with ${ }^{99 \mathrm{~m}} \mathrm{Tc}$ the nonradioactive rhenium analogue was produced and characterized. Metallacarboranes containing Re $\mathbf{7 3}$ and radiolabelled ${ }^{99 \mathrm{~m}} \mathrm{Tc} \mathbf{7 4}$ were synthesized via microwave assisted synthesis from the deboronated form of $\mathbf{1 8}$. The reaction time and yield of the products were improved by microwave heating at $200{ }^{\circ} \mathrm{C}$ using excess $\left[\mathrm{Re}(\mathrm{CO})_{3}\left(\mathrm{H}_{2} \mathrm{O}\right)_{3}\right] \mathrm{Br}$. Isomerization of cluster carbon atoms in $\mathbf{7 3}$ and $\mathbf{7 4}$ occurred during microwave irradiation and determined by nOe experiments. The migration of $\mathrm{C}$-atoms increases thermodynamic stability of the cluster and reduces steric interaction between large carbohydrate substituents and the metal tricarbonyl core. The nonradioactive iodinated carboranyl glycoside $\mathbf{7 5}$ was prepared by treating the deboronated form of $\mathbf{1 8}$ with $\mathrm{NaI}$ in the presence of chloramine- $\mathrm{T}$ whereas the radioiodination of compound $\mathbf{7 6}$ was performed in the presence $\mathrm{Na}\left[{ }^{125} \mathrm{I}\right][36]$.
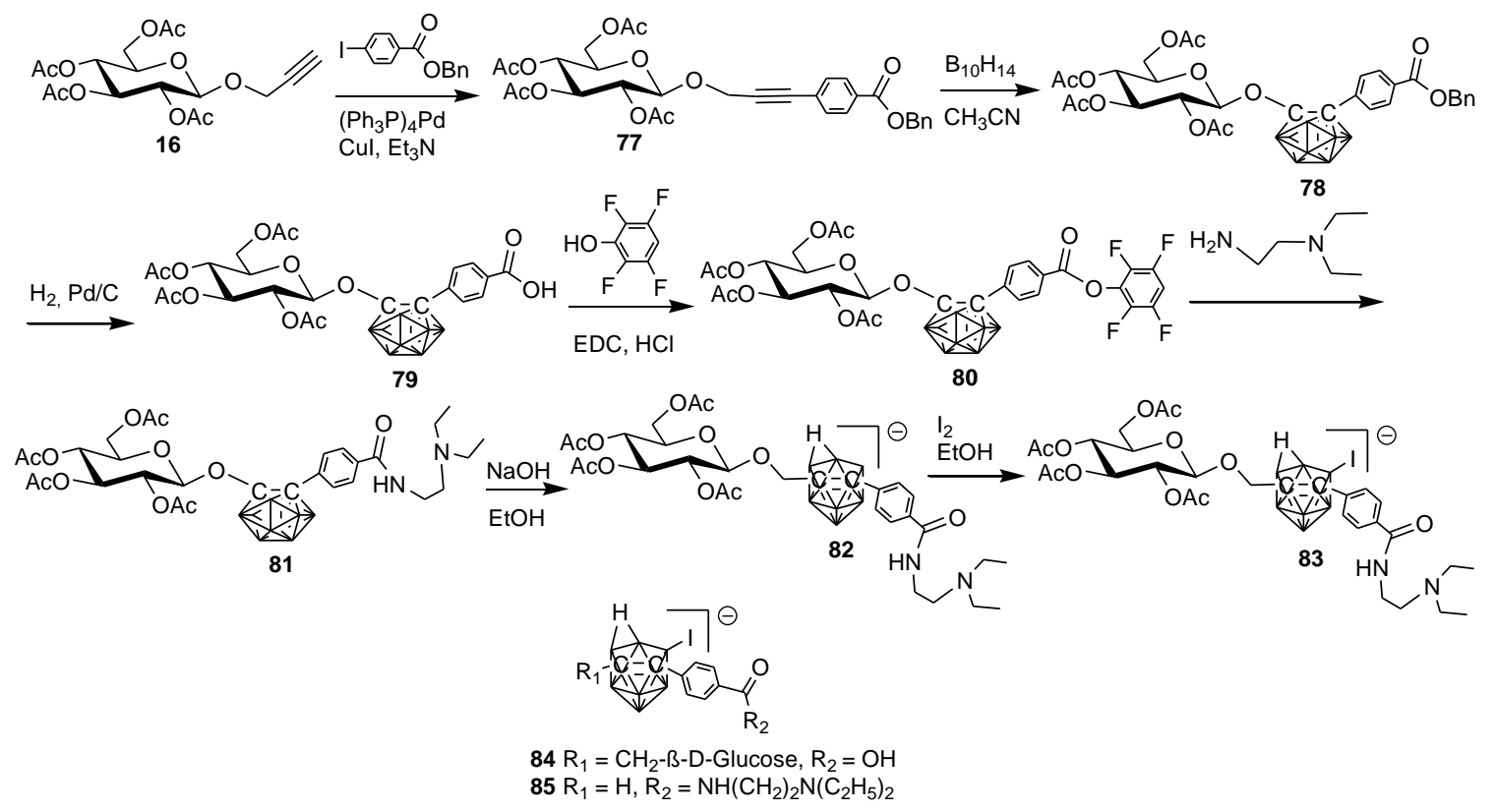

Scheme 8: Synthesis of iodo-nido-carborane derivatives for radiopharmaceutical applications 
The glycosylated target $\mathbf{8 2}$ was prepared using benzyl ester as protecting groups (Scheme 8). A Sonogashira type cross-coupling reaction between $\mathbf{1 6}$ and benzyl protected 4-iodo benzoic acid led to the formation of $\mathbf{7 7}$. After treating $\mathbf{7 7}$ with decaborane and subsequent deprotection of the benzyl group led to the formation of 79. The carboxylic acid group in 79 was converted to the corresponding ester $\mathbf{8 0}$ in the presence of $2,3,5,6$ tetrafluorophenol. Further treatment of $\mathbf{8 0}$ with $\mathrm{N}, \mathrm{N}$-diethylethylenediamine followed by deboronation led to the formation of nido-carborane derivative 82. The non-radioactive iodinated derivative $\mathbf{8 3}$ was synthesized by iodination of $\mathbf{8 2}$ with iodine in ethanol. The iodinated-nido-carboranyl derivatives $\mathbf{8 4}$ and $\mathbf{8 5}$ were synthesized in a likewise manner as described for $\mathbf{8 3}$ and radioiodination of $\mathbf{8 3 , 8 4}$ and $\mathbf{8 5}$ were carried out using $\mathrm{Na}$ [125I] [37]. Uptake of radio iodinated derivatives 83 and 85 were studied using murine B16F10 melanoma cells. The results showed that the glycosylated benzamide [125I]-83 bound poorly to the cells with a maximum binding being $0.62 \pm 0.11 \%$ after 24 hours of incubation. Whereas, $[125 \mathrm{I}]-\mathbf{8 5}$ showed improved uptake up to $30.7 \pm 2.2 \%$ after 24 hours. These results suggested that the increased hydrophilicity of the carbohydrate conjugate resulted in reduced uptake by the melanoma cells. In addition, the negative charge on the carborane also had a detrimental effect on binding [37].

\section{Glycoconjugates of dodecaborate ion}

To date, only a few papers report syntheses of carbohydrate conjugates with the dodecaborate anion 4 (Figure 1). This may be because of the synthetic difficulty of using this hydrophilic and high polar salt due to solubility problem. However, the hydrophilic nature of dodecaborate anion is an important criterion for choosing it for the synthesis of new boron delivery platforms because the presence of this anion makes the molecule 
water-soluble. In most cases, the use of halogen derivatives of carbohydrates such as 86, 88 and 92 (Schemes 9 and 10) have been used to synthesize conjugates of dodecaborate ion. However, the purification of the final dodecaborate-carbohydrate conjugates found to be challenging $[38,39]$.
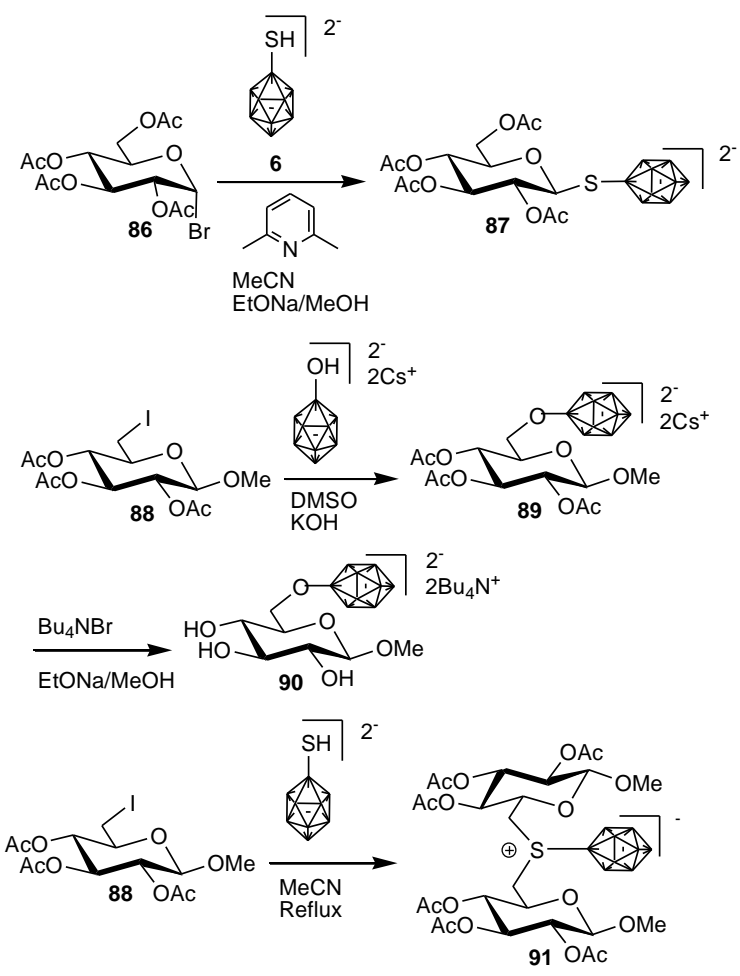

Scheme 9. Synthesis of glycoconjugates dodecaborate ion

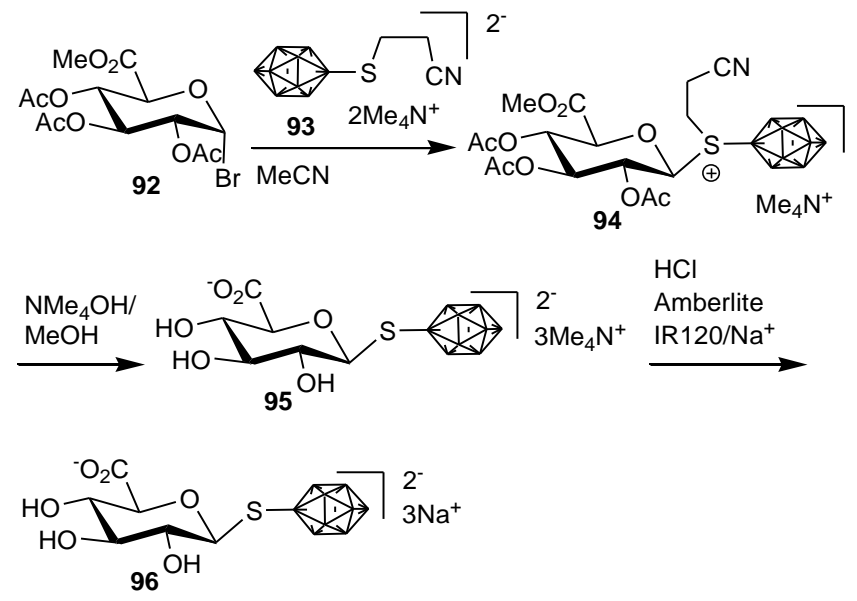

Scheme 10. Conjugate of dodecaborate ion with glucuronic acid 
Dodecaborate-carbohydrate conjugate containing glucuronic acid as the carbohydrate moiety has been synthesized starting from methyl glucopyranosyl bromide uronate $\mathbf{9 2}$ (Scheme 10). The synthesis was carried out by the Koenigs-Knorr reaction using 2Cyano-ethyl protected BSH 93 and 92 to obtain the $\beta$-anomer $\mathbf{9 4}$. After the deprotection of sulfur atom and the acetyl groups, subsequent replacement of toxic $\mathrm{Me}_{4} \mathrm{~N}^{+}$cation resulted the formation of desired compound 96 [40].

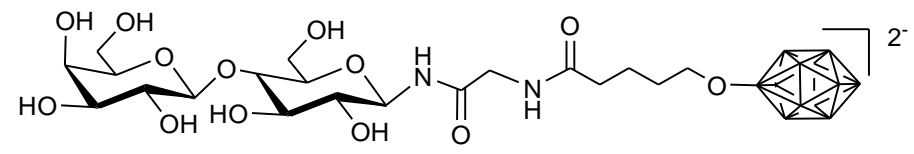

97

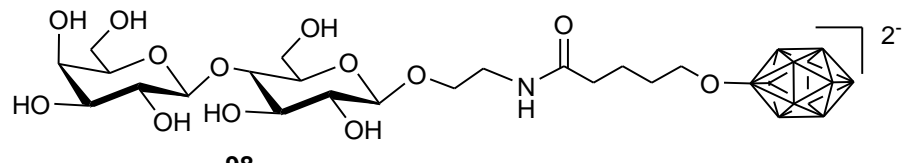

98

Figure 7. Conjugate of dodecaborate ion with oligosaccharide

A facile method for the synthesis of conjugates of polyhedral boron compounds with oligosaccharides such as lactose has also been reported. In this approach, lactose derivatives such as $N$-glycyl- $\beta$-lactosylamine and 2-aminoethyl lactoside have been treated with carboxylic derivative of closo-dodecaborate anion resulting in the formation of compounds 97 and 98 respectively (Figure 7) [41].

\section{Conjugates of carboranes with carbohydrate mimetics}

There are many problems associated with carbohydrates to use them for medicinal applications. Their hydrophilic characteristics make them orally unavailable. Due to lack of hydrophobic and charged moieties, carbohydrates bind to their receptors with weak affinity. Carbohydrates also possess labile glycosidic bonds, those are easily biodegraded. In addition, oligosaccharides are also prone to enzymatic degradation [42]. 


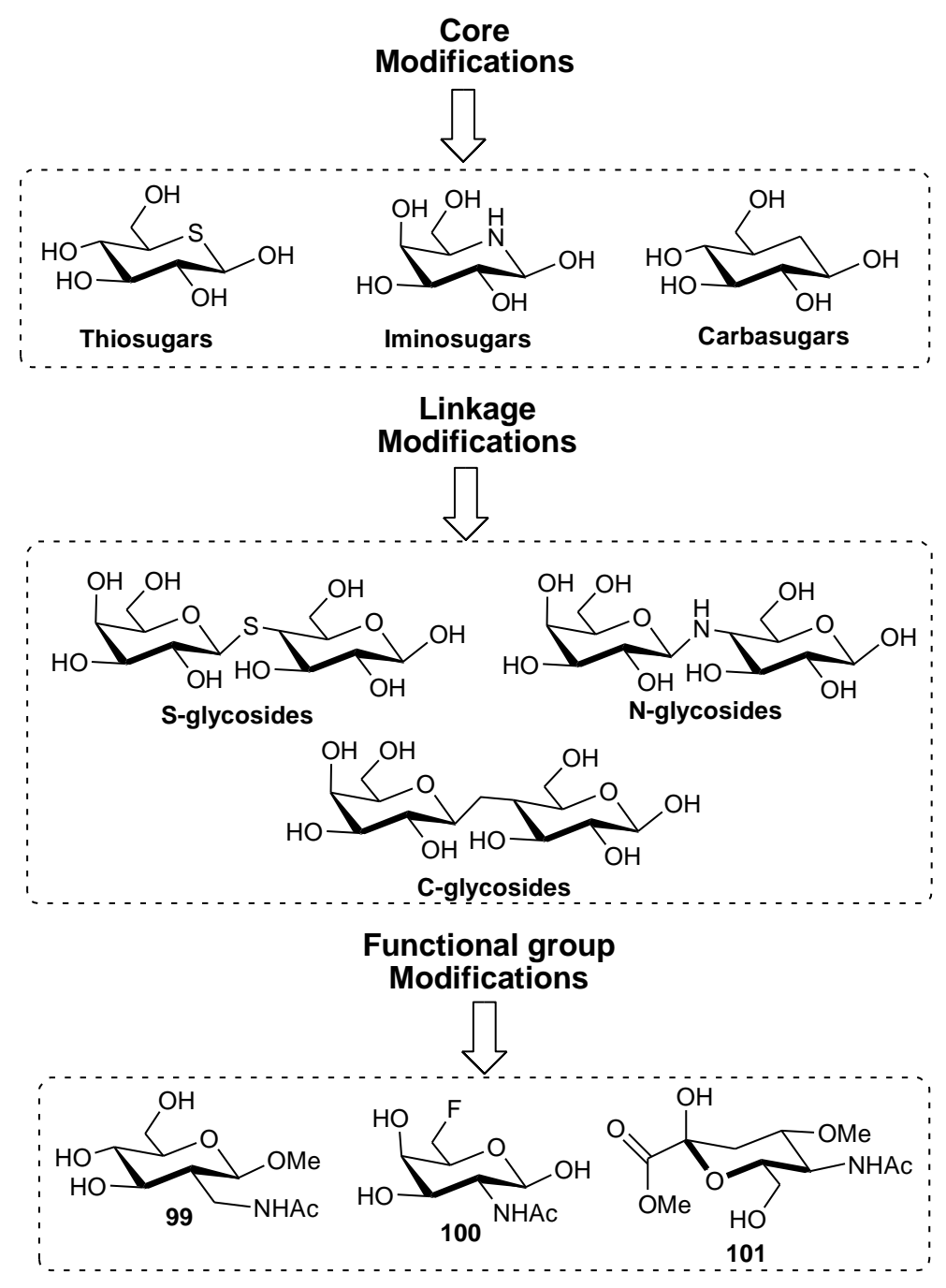

Figure 8. Carbohydrate mimetics

Therefore, to address the issues associated with the use of carbohydrates in drug research, the use of carbohydrate mimetics have gained considerable interest in recent years. Carbohydrate mimetics are typically prepared either by modification of the core or the ring or by the modification of the linkages between monosaccharide units. Typical core modifications include the replacement of oxygen with $-\mathrm{S}$, $-\mathrm{NH}$ or $-\mathrm{C}$ and common linkage modified carbohydrates are S-glycosides, N-glycosides, and C-glycosides as shown in Figure 8. The anomeric oxygen of a glycosidic linkage is replaced by sulfur, nitrogen or a carbon atom respectively $[43,44]$. Despite advancement in the chemistry of 
carbohydrate mimetics, conjugates of polyhedral boron compounds with carbohydrate mimetics and their biological evaluation have not been properly carried out.

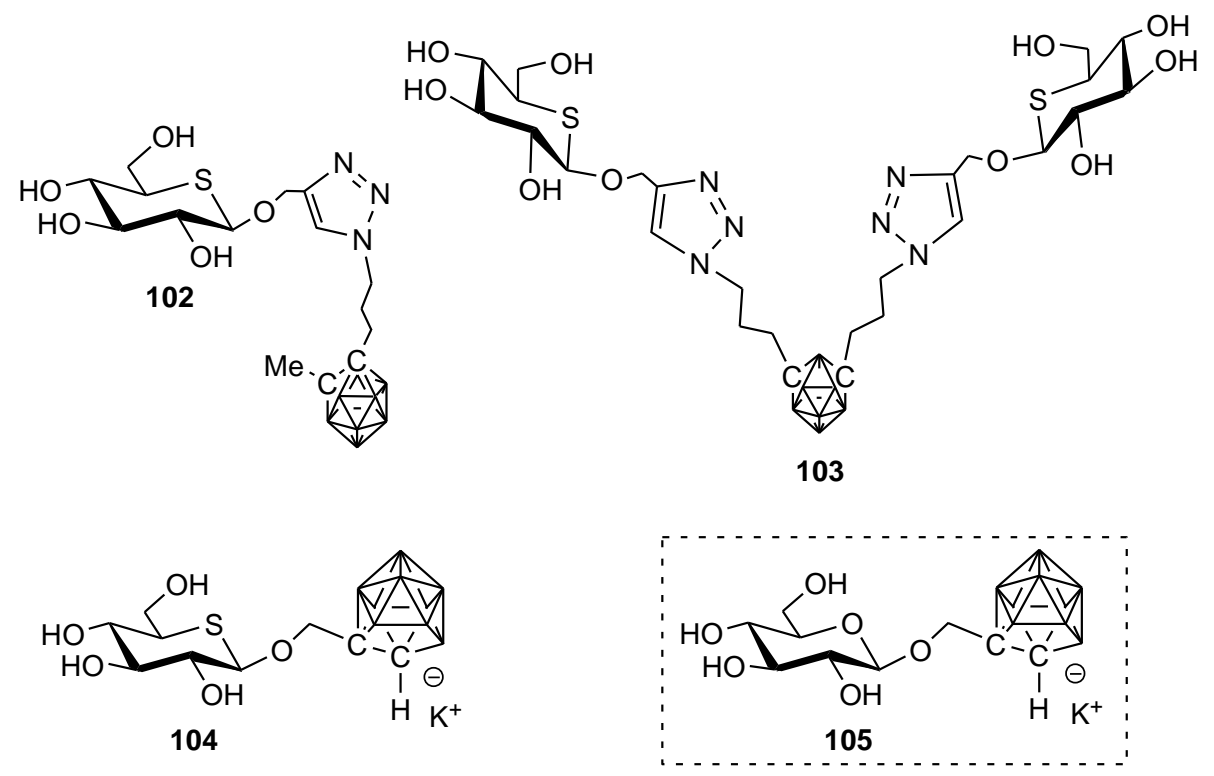

Figure 9. Conjugates of carborane with thiosugar

Recently, a series of carborane-appended 5-thio-D-glucopyranose (5-TDGP) derivatives containing one to two 5-TDGP moieties were synthesized via click cycloaddition reaction as well as following the traditional methods (Figure 9). Among the carboranyl-5-TDGP derivatives, the decapitated nido-carboranyl derivative 104 was found to be highly watersoluble and therefore its preliminary biodistribution study was conducted. A comparative biological evaluation of 104 versus its carboranyl-D-glucopyranose analog 105 with human hepatocellular carcinoma cells (SK-Hep1) indicated that 5-TDGP to be a better boron carrier than normal D-glucopyranose. The carboranyl-5-TDGP 104 showed nearly two fold increase in cellular boron accumulation than carboranyl-D-glucopyranose analog 105 over a period of 2 hours (Figure 10). The accumulation of both 104 and 105 were 
found to occur in a temperature dependent manner. The higher accumulation of $\mathbf{1 0 5}$ indicated that thiosugar could be a better boron carrier for future BNCT applications.

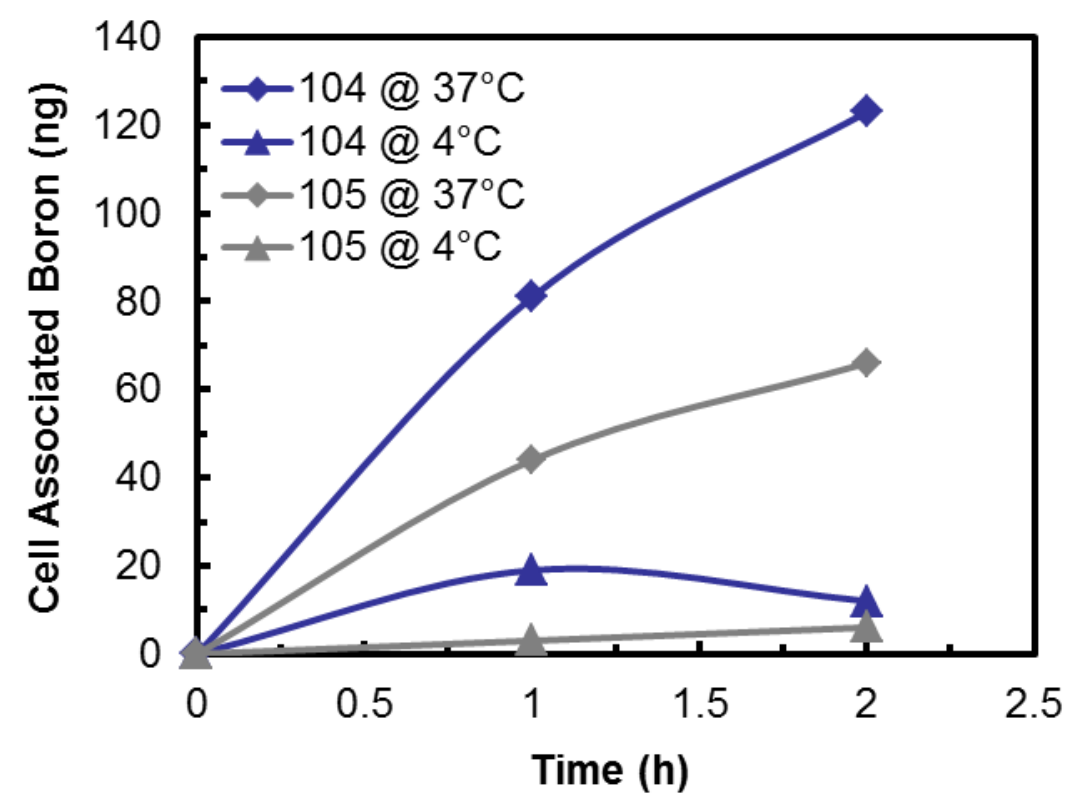

Figure 10. Temperature-dependent accumulation of carborane-appended thiosugar and sugar derivatives (104 and 105) to SK-Hep1 human hepatocellular carcinoma cells.

\section{Conclusions}

This review article summarizes the advances in the synthesis of glycoconjugates polyhedral boron clusters as potential agents for BNCT. In most of the cases, conjugates of carbohydrates with boron clusters have been found to be efficient boron delivery platform for targeted boron delivery for BNCT applications. However, in some cases the use of carbohydrates as drug delivery platform have failed to produce the desired results due to the enzymatic degradation and other relevant issues. To overcome these issues carbohydrate mimetics could be used for boron delivery to tumor tissues. Recent studies using thiosugar as boron carrier has shown better boron accumulation in human hepatocellular carcinoma cells. The study indicates carbohydrate mimetics could be 
better boron carrier for future medicinal applications. Nonetheless, further research is required in this area for the synthesis and biological evaluation of new and more effective carbohydrate-based boron delivery agents.

\section{Acknowledgment}

We gratefully acknowledge financial support from DST-SERB and UGC, Govt. of India. NSH acknowledges NSF for financial support.

\section{References}

(1) P. H. Seeberger, D. B. Werz, Nature 446 (2007) 1046.

(2) R. Roy, Curr. Opin. Struct. Biol. 6 (1996) 692.

(3) B. G Davis, M. A. Robinson, Curr. Opin. Drug Discov. Dev. 5 (2002) 279.

(4) M. S. Wadhwa, K. G. Rice, J. Drug Target. 3 (1995) 111.

(5) N. Yamazaki, S. Kojima, N. V. Bovin, S. André, S. Gabius, H-J. Gabius, Adv. Drug Deliv. Rev. 43 (2000) 225.

(6) A. Orlova, L. O. Kononov, Russ. Chem. Rev.78 (2009) 629.

(7) (a) R. Satapathy, B. P. Dash, J. A. Maguire and N. S. Hosmane, Collect. Czech. Chem. Commun.75 (2010) 995.

(b) C. Salt, A. J. Lennox, M. Takagaki, J. A. Maguire, N. S. Hosmane, Russ. Chem. Bull. Int. Ed. 53 (2004) 1871.

(c) A. H. Soloway, W. Tjarks, B. A. Barnum, F-G. Rong, R. F. Barth, I. M. Codogni, J. G. Wilson, Chem. Rev. 98 (1998) 1515.

(d) M. F. Hawthorne, A. Maderna, Chem. Rev. 99 (1999) 3421.

(8) (a) P. Cigler, M. Kozisek, P. Rezacova, J. Brynda, Z. Otwinowski, J. Pokorna, et al. Proc. Natl. Acad. Sci. U. S. A. 102 (2005) 15394. 
(b) M. Kozisek, P. Sigler, M. Lepsik, J. Fanfrlik, P. Rezacova, J. Brynda, et al. J. Med. Chem. 51 (2008) 4839.

(c) P. Rezacova, J. Pokorna, J. Brynda, M. Kozisek, P. Cigler, M. Lepsik, et al. J. Med. Chem. 52 (2009) 7132.

(9) (a) M. L. Beer, J. Lemon, J. F. Valliant, J. Med. Chem. 53 (2010) 8012.

(b) J. F. Valliant, P. Schaffer, K. A. Stephenson, J. F. Britten, J. Org. Chem. 67 (2002) 383.

(c) B. A. Wojtczak, A. B. Olejniczak, M. Przepiorkiewicz, A. Andrysiak, Z. J. Lesnikowski, Collect. Czech. Chem. Commun. 73 (2008) 175.

(d) K. Bednarska, A. B. Olejniczak, B. A. Wojtczak, Z. Sulowska, Z. J. Lesnikowski, ChemMedChem 5 (2010) 749.

(10) (a) J. A. Coderre, J. D. Glass, R. G. Fairchild, U. Roy, S. Cohen, I. Fand, Cancer Res. 47 (1987) 6377.

(b) P. J. Slootweg, G. J. Hordijk, Y. Schade, R. J. J. Van Es, R. Koole, Oral Oncol. 38 (2002) 500.

(c) M. Scholz, A. L. Blobaum, L. J. Marnett, E. Hey-Hawkins, Bioorg. Med. Chem. 19 (2011) 3242.

(d) V. C. Njar, L. Gediya, P. Purushottamachar, P. Chopra, T. S. Vasaitis, A. Khandelwal, J. Mehta, C. Huynh, A. Belosay, J. Patel, Bioorg. Med. Chem. 14 (2006) 4323.

(11) (a) M. Scholz, E. Hey-Hawkins, Chem. Rev. 111 (2011) 7035.

(b) M. Scholz, G.N. Kaluderovoc, H. Kommera, R. Paschke, J. Will, W. S. Sheldric, E. Hey-Hawkins, Eur. J. Med. Chem. 46 (2011) 1131. 
(c) Y. Endo, T. Yoshimi, T. Iijima, Y. Yamakoshi, Bioorg. Med. Chem. Lett. 9 (1999) 3387.

(d) Y. Endo, T. Iijima, Y. Yamakoshi, M. Yamaguchi, H. Fukasawa, K. Shudo, J. Med. Chem. 42 (1999) 1501.

(12) (a) R. A. Watson-Clark, M. L. Banquerigo, K. Shelly, M. F. Hawthorne, E. Branh, Proc. Natl. Acad. Sci. U.S.A. (1998) 2531.

(b) K. Ohta, T. Iijima, E. Kawachi, H. Kagechika, Y. Endo, Bioorg. Med. Chem. Lett. 14 (2004) 5913.

(c) S. Fujii, K. Ohta, T. Goto, H. Kagechika, Y. Endo, Bioorg. Med. Chem. 17 (2009) 344.

(d) T. Goto, K. Ohta, S. Fujii, S. Ohta, Y. Endo, J. Med. Chem. 53 (2010) 4917.

(13) (a) B. P. Dash, R. Satapathy, J. A. Maguire and N. S. Hosmane, Org. Lett. 10 (2008) 2247.

(b) R. Satapathy, B. P. Dash, C. Zheng, J. A. Maguire and N. S. Hosmane, J. Org. Chem. 76 (2011) 3562.

(c) B. P. Dash, R. Satapathy, B. P. Bode, C. T. Reidl, J. W. Sawicki, A. J. Mason, J. A. Maguire and N. S. Hosmane, Organometallics 31 (2012) 2931.

(14) (a) N. S. Hosmane (Ed.), Boron Science: New Technologies and Applications, CRC Press, Boca Raton, 2011 and Chapters therein.

(b) I. B. Sivaev, V. V. Bregadze, Eur. J. Inorg. Chem. (2009) 1433.

(c) Z. J. Lesnikowski, Collect. Czech. Chem. Commun. 72 (2007) 1646.

(15) (a) J. F. Valliant, K. J. Guenther, A. S. King, P. Morel, P. Schaffer, O. O. Sogbein, K. A. Stephenson, Coord. Chem. Rev. 232 (2002) 173. 
(b) M. C. Parrott, E. B. Marchington, J. F. Valliant, A. Adronov, J. Am. Chem. Soc. 127 (2005), 12081.

(16) (a) R. Satapathy, B. P. Dash, J. A. Maguire and N. S. Hosmane, Dalton Trans. 39 (2010), 6613.

(b) B. P. Dash, R. Satapathy, J. A. Maguire and N. S. Hosmane, New J. Chem. 35 (2011) 1955.

(c) B. P. Dash, R. Satapathy, E. R. Gaillard, K. M. Norton, J. A. Maguire and N. S. Hosmane, Inorg. Chem. 50 (2011) 5485.

(d) B. P. Dash, R. Satapathy, E. R. Gaillard, J. A. Maguire and N. S. Hosmane, J. Am. Chem. Soc. 132 (2010), 6578.

(e) B. P. Dash, R. Satapathy, J. A. Maguire and N. S. Hosmane, Chem. Commun. (2009) 3267.

(f) B. P. Dash, R. Satapathy, J. A. Maguire and N. S. Hosmane, Organometallics 29 (2010) 5230.

(17) J. L. Maurer, A. J. Serino, M. F. Hawthorne, Organometallics 7 (1988) 2519.

(18) W. Tjarks, A. K. M. Anisuzzaman, L. Liu, A. H. Soloway, R. F. Barth, D. J. Perkins, D. M. Adams, J. Med. Chem. 35 (1992) 1628.

(19) L. F. Tietze, U. Bothe, Chem. Eur. J. 4 (1998) 1179.

(20) L. F. Tietze, U. Bothe, U. Griesbach, M. Nakaichi, T. Hasegawa, H. Nakamura, Y. Yamamoto, Bioorg. Med. Chem. 9 (2001) 1747.

(21) G. B. Giovenzana, L. Lay, D. Monti, G. Palmisano, L. Panza, Tetrahedron 55 (1999) 14123. 
(22) L. F. Tietze, U. Bothe, U. Griesbach, M. Nakaichi, T. Hasegawa, H. Nakamura, Y. Yamamoto, ChemBioChem 2 (2001) 326.

(23) L. F. Tietze, U. Griesbach, I. Schuberth, U. Bothe, A. Marra, A. Dondoni, Chem. Eur. J. 9 (2003) 1296.

(24) S. Ronchi, D. Prosperi, F. Compostella, L. Panza, Synlett (2004), 1007.

(25) A. V. Orlova, L. O. Kononov, B. G. Kimel, I. B. Sivaev, V. I. Bregadze, Appl. Organometal. Chem. 20 (2006) 416.

(26) A. R. Genady, M. E. El-Zaria, Appl. Organometal. Chem. 22 (2008) 227.

(27) S. Stadlbauer, P. Welzel, E. Hey-Hawkins, Inorg. Chem. 48 (2009) 5005.

(28) S. Stadlbauer, P. Lonnecke, P. Welzel, E. Hey-Hawkins, Eur. J. Org. Chem. (2009) 6301.

(29) S. Stadlbauer, P. Lonnecke, P. Welzel, E. Hey-Hawkins, Eur. J. Org. Chem. (2010) 3129.

(30) (a) F. Campo, M. Mossotti, L. Panza, Synlett 23 (2012) 120.

(b) L. M. Likhosherstov, O. S. Novikova, L. O. Kononov, I. B. Sivaev, V. I. Bregadze, Russ. Chem. Bull. Int. Ed. 58 (2009) 446.

(c) L. M. Likhosherstov, O. S. Novikova, L. O. Kononov, A. O. Chizhov, I. B.

Sivaev, V. I. Bregadze, Russ. Chem. Bull. Int. Ed. 59 (2010) 2297.

(d) L. M. Likhosherstov, O. S. Novikova, A. O. Chizhov, I. B. Sivaev, V. I. Bregadze, Russ. Chem. Bull. Int. Ed. 60 (2011) 2359.

(31) D. J. A. Margolis, J. M. Hoffman, R. J. Herfkens, A. Quon, and S. S. Gambhir. Radiology 245 (2007) 333. 
(32) (a) B. M. Gallagher, A. Ansari, H. Atkins, V. Casella, D. R. Christman, J. S. Fowler, T. Ido, R. R. MacGregor, P. Som, C.-N. Wan, A. P. Wolf, D. E. Kuhl, M. Reivich, J. Nucl. Med. 18 (1977) 990.

(b) O. Couturier, A. Luxen, J.-F. Chatal, J.-P. Vuillez, P. Rigo, R. Hustinx, Eur. J. Nuc. Med. Mol. Imaging 31 (2004) 1182.

(33) (a) M. Corsini, F. F. de Biani, P. Zanello, Coord. Chem. Rev. 250 (2006) 1351.

(b) M. F. Hawthorne, D. C. Young, T. D. Andrews, D. V. Howe, R. L. Pilling, A. D. Pitts, M. Rintjes, L. F. Warren, Jr., P. A. Wegner, J. Am. Chem. Soc. 90 (1968) 879.

(34) S. S. Jurisson, J. D. Lydon, Chem. Rev. 99 (1999) 2205.

(35) O. O. Sogbein, A. E. C. Green, P. Schaffer, R. Chankalal, E. Lee, B. D. Healy, P. Morel, J. F. Valliant, Inorg. Chem. 44 (2005) 9574.

(36) A. E. C. Green, L. E. Harrington, J. F. Valliant, Can. J. Chem. 86 (2008) 1063.

(37) A. E. C. Green, S. K. Parker, J. F. Valliant, J. Organomet. Chem. 694 (2009) 1736.

(38) D. Gabel, S. Harfst, D. Moller, H. Ketz, T. Peymann, J. Rosler, in: G. W. Kabalka (Ed.), Current Topics in the Chemistry of Boron, Royal Society of Chemistry, Cambridge, 1994, p. 161.

(39) T. Peymann, D. Preusse, D. Gabel, in: B. Larson, J. Crawford R. Weinreich (Eds.), Advances in Neutron Capture Therapy Vol. II, Elsevier, Amsterdam, 1997, p. 35.

(40) B. Lechtenberg, D. Gabel, J. Organomet. Chem. 690 (2005), 2780.

(41) A. V. Orlova, N. N. Kondakov, A. I. Zinin, B. G. Kimel, L. O. Kononov, I. B. Sivaev and V. I. Bregadze, Russ. J. Bioorg. Chem. 32 (2006), 568.

(42) (a) H. J. M. Gijsen, L. Qiao, W. Fitz, C.-H. Wong, Chem. Rev. 96 (1996), 443; 
(b) C.-H. Wong, Acc. Chem. Res. 32 (1999), 376.

(43) D. C. Koester, A. Holkenbrink, D. B. Werz, Synthesis 19 (2010) 3217.

(44) V. H. Lillelund, H. H. Jensen, X. Liang, M. Bols, Chem. Rev. 102 (2002) 515.

(45) R. Satapathy, B. P. Dash, B. P. Bode, E. A. Byczynski, S. N. Hosmane, S. Bux, N. S. Hosmane, Dalton Trans, 41 (2012) 8982. 
Graphical abstract

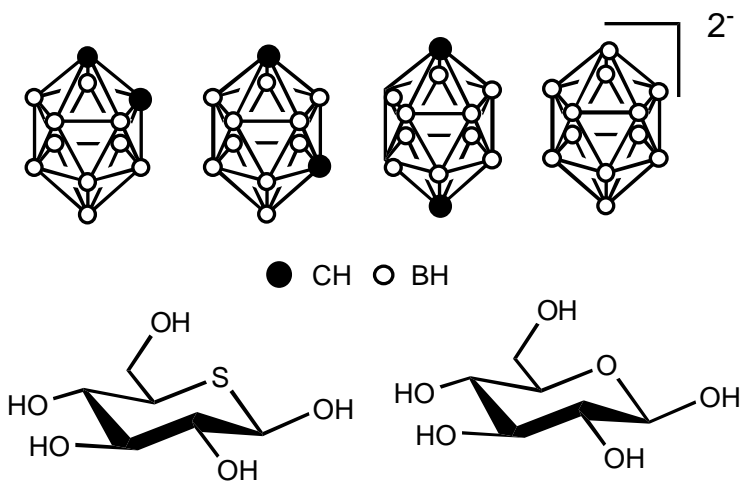

